\title{
Rapid-Onset Obesity With Hypothalamic Dysfunction, Hypoventilation, and Autonomic Dysregulation: Analysis of Hypothalamic and Autonomic Candidate Genes
}

\author{
CASEY M. RAND, PALLAVI P. PATWARI, EKATERINA A. RODIKOVA, LILI ZHOU, ELIZABETH M. BERRY-KRAVIS, \\ RICHARD J. A. WILSON, TORBEN BECH-HANSEN, AND DEBRA E. WEESE-MAYER
}

Department of Pediatrics [C.M.R., P.P.P., D.E.W.-M.], Children's Memorial Hospital, Chicago, IL 60614; Departments of Physiology and Biophysics [E.A.R., R.J.A.W.] and Medical Genetics [T.B.-H.], Hotchkiss Brain Institute and Institute of Maternal and Child Health, University of Calgary, AB T2N 4N1, Canada; Departments of Pediatrics, Neurological Sciences and Biochemistry [L.Z., E.M.B.-K.], Rush University Medical Center, Chicago, IL 60612

\begin{abstract}
Rapid-onset Obesity with Hypothalamic Dysfunction, Hypoventilation, and Autonomic Dysregulation (ROHHAD) is a rare and complex pediatric disorder. Despite increased identification and advancing knowledge of the disease course, the variable onset and timing of phenotypic features in ROHHAD often result in delayed or missed diagnosis, potentially leading to fatal central hypoventilation, cardiorespiratory arrest, and impaired neurocognitive development. The 5-hydroxytryptamine receptor $1 \mathrm{~A}\left(H T R_{1 A}\right)$, orthopedia $(O T P)$, and pituitary adenylate cyclase activating polypeptide (PACAP) genes were targeted in the etiology of ROHHAD based on their roles in the embryologic development of the hypothalamus and autonomic nervous system. We hypothesized that variations of $H T R_{I A}$, OTP, and/or PACAP would be associated with ROHHAD. All coding regions and intron-exon boundaries of the $H T R_{I A}, O T P$, and PACAP genes, in addition to the promoter region of the $H T R_{1 A}$ gene, were analyzed by standard sequencing in 25 ROHHAD cases and 25 matched controls. Thirteen variations, including six protein-changing mutations, were identified. None of these variations were significantly correlated with ROHHAD. This report provides evidence that variation of the $H T R_{1 A}, O T P$, and PACAP genes are not responsible for ROHHAD. These results represent a further step in the investigation of the genetic determinants of ROHHAD. (Pediatr Res 70: 375-378, 2011)
\end{abstract}

$R^{2}$ apid-onset Obesity with Hypothalamic Dysfunction, Hypoventilation, and Autonomic Dysregulation (ROHHAD), formerly known as Late-Onset Central Hypoventilation with Hypothalamic Dysfunction, is a rare and complex pediatric disorder for which rapid weight gain is often a harbinger of potentially fatal central hypoventilation. Since the first published description in 1965 (1), ROHHAD has often been associated and confused with Congenital Central Hypoventilation Syndrome (CCHS), specifically later-onset CCHS (LO-CCHS). However, the clinical distinction of ROHHAD from LO-CCHS (2), coupled with the discovery of mutations in the paired-like homeobox $2 \mathrm{~B}(\mathrm{PHOX} 2 \mathrm{~B})$ gene as disease-

Received February 7, 2011; accepted April 12, 2011.

Correspondence: Debra E. Weese-Mayer, M.D., Center for Autonomic Medicine in Pediatrics, Children's Memorial Hospital, 2300 Children's Plaza, Box \#165, Chicago, IL 60614; e-mail: DWeese-Mayer@ChildrensMemorial.org

Supported by the ROHHAD Fight Inc., Scott R. Conlon ROHHAD Research Fund, the Chicago Community Trust Foundation, the Alberta Innervates Health Solution, Canadian Institute of Health Research, and Calgary SIDS. defining in CCHS and LO-CCHS (3-7), and the subsequent lack of these mutations in ROHHAD subjects $(8,9)$, established the distinction between these clinical entities. Since the summary of Katz et al. (2) in 2000, describing the 10 previously reported cases of ROHHAD and one new case, more than 65 new cases have been reported in the literature $(2,8-$ 12). Accordingly, knowledge of the clinical presentation and clinical course has significantly advanced with detailed descriptions of the phenotype in the world's largest cohorts (8-10) and creation of the acronym ROHHAD to aid diagnosis (8). Despite these advances, the outcome remains variable for ROHHAD patients and diagnosis outside of the few centers with substantial ROHHAD experience remains difficult. Delayed diagnosis can lead to potentially fatal central hypoventilation and impaired neurocognitive development. In addition, 50-60\% of the patients have suffered from cardiorespiratory arrest. The prognosis of these children is greatly improved, however, with early identification of the phenotype. As such, development and advancement of diagnostic methods deserves further investigation.

The consistency in symptoms and presentation of the ROHHAD phenotype, coupled with previous reports of familial occurrence (9), has led to a high suspicion for a genetic etiology. However, previous candidate gene studies have failed to identify a disease-associated genetic variation and are limited by small sample size (Table 1). These investigations have focused on genes involved in development and function of the hypothalamic, autonomic, and/or neuroendocrine systems due to deficiencies of these systems in ROHHAD.

As altered development or maintenance of the hypothalamic, autonomic, and neuroendocrine systems remain strong candidates for the developmental basis of ROHHAD, genes central to the function of these systems continue to be targeted

\footnotetext{
Abbreviations: ANS, autonomic nervous system; CCHS, Congenital Central Hypoventilation Syndrome; CMH, Children's Memorial Hospital; $\boldsymbol{H T R}_{\boldsymbol{1 A}}$, 5-hydroxytryptamine (serotonin) receptor 1A; LO-CCHS, later onset-Congenital Central Hypoventilation Syndrome; $\boldsymbol{O T P}$, orthopedia; PACAP, pituitary adenylate cyclase activating polypeptide; ROHHAD, rapid-onset obesity with hypothalamic dysfunction, hypoventilation, and autonomic dysregulation; RUMC, Rush University Medical Center
} 
Table 1. Previously reported candidate gene studies in ROHHAD

\begin{tabular}{llcc}
\hline \multicolumn{1}{c}{ Gene } & \multicolumn{1}{c}{ Function } & Reference & $\begin{array}{c}\text { Number of } \\
\text { subjects }\end{array}$ \\
\hline NECDIN & Hypothalamic/respiratory & 9 & 10 \\
ASCL1 & Neuroendocrine & 9 & 10 \\
PHOX2B & Respiratory/autonomic & 8,9 & $15 / 10$ \\
TRKB & $\begin{array}{c}\text { Neuronal development/ } \\
\text { synaptic plasticity }\end{array}$ & 8 & 15 \\
BDNF & $\begin{array}{c}\text { Neuronal development/ } \\
\text { synaptic plasticity }\end{array}$ & 8 & 15 \\
& & & \\
\hline
\end{tabular}

as candidate genes in ROHHAD etiology. The 5-hydroxytryptamine (serotonin) receptor $1 \mathrm{~A}\left(H T R_{I A}\right)$ shows hypothalamic expression and has a known role in appetite control and energy regulation (13). Furthermore, this gene is densely distributed in medullary regions important for cardiorespiratory regulation and has a key role in the autonomic response to homeostatic stress $(14,15)$. Like $H T R_{1 A}$, the orthopedia $(O T P)$ gene shows hypothalamic expression, with an important role in hypothalamic cell specification in the developing hypothalamus (16). The paraventricular nucleus complex of the hypothalamus, important in homeostatic control functions, has also been shown to express OTP (16). Pituitary adenylate cyclase activating polypeptide $(P A C A P)$ is expressed in brain regions important to respiratory, cardiovascular, visceral, and thermoregulatory control including the paraventricular nucleus complex of the hypothalamus (17-20). PACAP has also been shown to be essential for normal lipid and carbohydrate metabolism (21) as well as maintenance of normal energy homeostasis (22). PACAP also plays an important role in respiratory chemosensitivity and preventing neonatal hypoventilation at reduced body temperatures $(23,24)$.

The variable onset and timing of phenotypic features in ROHHAD often result in delayed or missed diagnosis. Discovery of a diagnostic test for ROHHAD has great potential to decrease morbidity and mortality and improve the overall patient outcome. In addition, ascertainment of the etiology of ROHHAD would improve understanding of development of the hypothalamic and autonomic systems and their roles in feeding behavior and respiratory control and would allow consideration of mechanistically targeted treatment strategies. The $H T R_{I A}, O T P$, and PACAP genes were targeted as candidate genes in the etiology of ROHHAD based on their roles in the embryologic development of the hypothalamic, au- tonomic, and/or neuroendocrine systems. In addition, these genes have known roles in homeostasis, respiratory control, metabolism, and thermal regulation, all processes which appear to be dysfunctional in ROHHAD. We hypothesized that variations within coding regions of the $H T R_{I A}, O T P$, and/or PACAP genes would be associated with ROHHAD.

\section{METHODS}

Case identification. Twenty-five individuals with clinical features consistent with ROHHAD who were referred to Children's Memorial Hospital $(\mathrm{CMH})$ or Rush University Medical Center (RUMC) for clinical or genetic assessment were identified for inclusion in this study (15/25 cases included in previous ROHHAD genetics studies; Table 1) (8). Medical records for each proband were reviewed to determine the shared characteristics of ROHHAD. All cases were tested and confirmed negative for any known PHOX2B gene mutations (methodology provided below). Additional testing or records were requested on a case-by-case basis to ensure uniform clinical assessments. A subset of the children completed comprehensive evaluation at the Center for Autonomic Medicine in Pediatrics at $\mathrm{CMH}$ or previously at the Pediatric Respiratory Physiology Laboratory at RUMC.

Criteria for preliminary diagnosis. The criteria for diagnosis of ROHHAD included: onset of alveolar hypoventilation after the age of $1.5 \mathrm{y}$ and evidence of hypothalamic dysfunction, as defined by $\geq 1$ of the following findings: rapid onset obesity, hyperprolactinemia, central hypothyroidism, disordered water balance, failed growth hormone stimulation test, corticotropin deficiency, or delayed or precocious puberty.

Matched control identification. A three-generation family history was obtained for gender- and ethnicity-matched, unrelated living controls to ensure that there was no personal or family history of SIDS, Hirschsprung disease, CCHS, a tumor of neural crest origin, or a primary (nonacquired) disorder of the autonomic nervous system (ANS).

PCR and sequencing. Blood samples were obtained from individuals determined to have ROHHAD and gender- and ethnicity-matched controls. Genomic DNA was isolated using a Puregene reagent kit (Qiagen; Hilden, Germany) from white blood cells. Sequencing of the PHOX2B gene was performed as previously described (5). All coding regions and intron-exon boundaries of the $H T R_{1 A}, O T P$, and $P A C A P$ genes, in addition to the promoter region of the $H T R_{I A}$ gene, were PCR-amplified and analyzed by standard sequencing in 25 ROHHAD cases and 25 gender- and ethnicity-matched controls. Primer sequences were designed using PrimerQuest or Primer 3 software (Table 2). All participants signed informed consent for sample donation and participation in genetic studies according to $\mathrm{CMH}$ and/or RUMC institutional review board-approved protocols.

Statistical analyses. For each case-control comparison, we computed the standard $\chi^{2}$ tests of independence between the allelic distributions and ROHHAD phenotype. The difference in the number of index alleles in the cases and controls was compared by the Wilcoxon signed-rank test. Significance was applied at $p<0.05$.

\section{RESULTS}

Cohort identification for ROHHAD cases. The 25 ROHHAD cases identified for inclusion in this study included

Table 2. PCR and sequencing primers for genes examined in this study

\begin{tabular}{|c|c|c|c|c|}
\hline Gene & Region & Forward $\left(5^{\prime}-3^{\prime}\right)$ & Reverse $\left(5^{\prime}-3^{\prime}\right)$ & Sequencing $\left(5^{\prime}-3^{\prime}\right)$ \\
\hline \multirow[t]{4}{*}{$H T R_{1 A}$} & Promoter & GCTGGACTGTTAGATGATAACGGAGG & CCTGAAAGCTGCTCCTCGGAGATA & GCTGGACTGTTAGATGATAACGGAGG \\
\hline & & & & CCTGAAAGCTGCTCCTCGGAGATA \\
\hline & Exon 1 & ATTCCСТTCCTCCGAAACTTCCCA & TCATCACTGGCGGCAGAACTTACA & АTTCССТTCСТCCGAAACTTCCCA \\
\hline & & & & GACGCATGCACCATTAGCAAGGAT \\
\hline \multirow[t]{3}{*}{ OTP } & Exon 1 & TGGTCAAAGCCTTCTCCTCAAGCA & TATCCACGATACCAAAGCAGGGCA & TGGTCAAAGCCTTCTCCTCAAGCA \\
\hline & & & & TGCAGCGCCAAGGACTACATTTAC \\
\hline & & & & TGAACACCGACCACATCCTCTACA \\
\hline \multirow[t]{4}{*}{ PACAP } & $\begin{array}{r}\text { Promoter/ } \\
\text { Exon } 1\end{array}$ & AGCGCAGGAACGTGAAGAAG & CAAAGGACTGCAGGAAGGAG & AGCGCAGGAACGTGAAGAAG \\
\hline & Exon 2 & CGCGAGCCCCTTACTTTGGA & AAAATCCTGGGTGGGTCACC & CGCGAGCCCCTTACTTTGGA \\
\hline & Exon 3 & CTCTGGAGGTTTCCCTGTCA & TGCCACTTCAAAATCTCCAA & CTCTGGAGGTTTCCCTGTCA \\
\hline & Exon 4 & GCGATTGAACCTGTGTCTCC & ACACGAGCGATGACTGTTGA & GCGATTGAACCTGTGTCTCC \\
\hline
\end{tabular}


Table 3. Polymorphisms identified in 25 ROHHAD cases and 25 matched controls

\begin{tabular}{|c|c|c|c|c|c|c|c|}
\hline Gene & $\mathrm{RS}^{*}$ & Location & $\begin{array}{l}\text { Allele } \\
\text { change }\end{array}$ & Protein & Protein effect & $\begin{array}{l}\text { ROHHAD rare } \\
\text { allele frequency } \dagger\end{array}$ & $\begin{array}{l}\text { Control rare } \\
\text { allele frequency } \dagger\end{array}$ \\
\hline \multirow{5}{*}{$H T R_{I A}$} & rs1799921 & Exon 1 & $82 \mathrm{~A}>\mathrm{G}$ & 28 & Ile/Val & 0.02 & 0.02 \\
\hline & rs6294 & Exon 1 & $294 \mathrm{~A}>\mathrm{G}$ & 98 & $\mathrm{Val} / \mathrm{Val}$ & 0.12 & 0.18 \\
\hline & rs1800043 & Exon 1 & $552 \mathrm{C}>\mathrm{T}$ & 184 & Pro/Pro & 0.02 & 0.04 \\
\hline & rs1800042 & Exon 1 & $818 \mathrm{~A}>\mathrm{G}$ & 273 & Asp/Gly & 0.02 & 0.00 \\
\hline & $1^{*}$ & Exon 1 & $899 \mathrm{~A}>\mathrm{G}$ & 300 & Asn/Ser & 0.00 & 0.02 \\
\hline \multirow[t]{2}{*}{ OTP } & $2^{*}$ & Intron 1 & IVS1-85 C $>$ T & - & - & 0.02 & 0.00 \\
\hline & rs62362480 & Intron 2 & IVS2-32 $\mathrm{T}>\mathrm{G}$ & - & - & 0.46 & 0.42 \\
\hline \multirow[t]{6}{*}{ PACAP } & rs1893154 & Promoter & $\mathrm{G}>\mathrm{A}$ & - & - & 0.14 & 0.18 \\
\hline & rs1893153 & Promoter & $\mathrm{T}>\mathrm{A}$ & - & - & 0.36 & 0.34 \\
\hline & rs8192597 & Exon 2 & $\mathrm{~A}>\mathrm{G}$ & 42 & Ala/Ala & 0.40 & 0.41 \\
\hline & rs2856966 & Exon 2 & $\mathrm{~A}>\mathrm{G}$ & 54 & Asp/Gly & 0.28 & 0.28 \\
\hline & rs2231185 & Intron 2 & $\mathrm{~A}>\mathrm{T}$ & - & - & 0.10 & 0.07 \\
\hline & rs2231187 & Exon 4 & $\mathrm{~A}>\mathrm{G}$ & 575 & Lys/Lys & 0.22 & 0.22 \\
\hline
\end{tabular}

* Previously unreported variations.

$\dagger p>0.05$ for all ROHHAD $v s$ control, allele frequency comparisons.

14 females and 11 males (20 Caucasian, 3 Asian, and 2 Hispanic).

HTR $_{1 \mathrm{~A}}$ gene. Five protein-changing variations (Table 3) were identified in our cohort. No significant differences in frequency of these variations were observed between cases and controls. Overall, nine ROHHAD cases and 13 controls carried at least one $H T R_{I A}$ variation.

OTP gene. Two variations (Table 3) were identified in our cohort. No significant differences in frequency were observed between cases and controls. Overall, 23 ROHHAD cases and 21 controls carried one or both of these OTP variations.

PACAP gene. Six variations, including 1 protein-changing missense mutation, were identified in this study (Table 3). Significant differences were not observed between ROHHAD cases and controls for frequency of any of these variations.

\section{DISCUSSION}

Based on the common phenotypic profile of known ROHHAD cases and our hypothesis that genes involved in hypothalamic, autonomic, and/or neuroendocrine system development and regulation could cause or contribute to the development of ROHHAD, the $H T R_{I A}, O T P$, and PACAP genes were analyzed for disease-associated variation. Thirteen variations were identified within this cohort of 25 ROHHAD cases and 25 matched controls. However, none of the variants identified in this study was significantly associated with ROHHAD. Although this study did not identify ROHHAD-associated variations in any of these genes, it is possible that variation in genes coding for proteins acting elsewhere in the pathways/networks within which $H T R_{I A}, O T P$, and $P A C A P$ function may be involved in the etiology of ROHHAD.

Autoimmune and paraneoplastic mechanisms for ROHHAD have also been suggested. Particular consideration has been given to the possibility that ROHHAD may be a paraneoplastic condition $(12,25,26)$ based on the finding that neural crest tumors occur in $\sim 30-50 \%$ of reported cases $(8-10)$. Paraneoplastic conditions are disorders resulting from secondary autoimmune responses triggered by the presence of a tumor in the body and can be successfully treated with immunosuppressive therapy and/or tumor removal. Tumors of neural crest origin are well known to trigger paraneoplastic phenomena, including conditions such as opsoclonus-myoclonus syndrome. Recently, Paz-Priel et al. (12) described a single case with some symptoms suggestive of ROHHAD in which highdose cyclophosphamide, an immunosuppressive drug, was given with broad clinical improvement. As this case did not present with the hypoventilation typical of ROHHAD, it is not clear how relevant this result can be to the broader ROHHAD population. The finding does support the need for additional analysis of the hypothesis that ROHHAD may be a paraneoplastic condition, at least in a subset of cases. However, tumors have not been identified in more than $50 \%$ of reported ROHHAD cases. In addition, tumor removal in the subset of ROHHAD cases with tumors has failed to alter the other features of the phenotype, and immunosuppressive strategies have produced mixed results (26). Furthermore, the autoantibodies in serum and cerebrospinal fluid that characterize paraneoplastic syndromes have not yet been identified in the few cases of ROHHAD studied (26). However, tumors are often difficult to detect and in other paraneoplastic conditions cases have presented with disease in which tumors and autoantibodies could not be identified, at least initially, after the onset of disease symptoms $(27,28)$. It is also possible that ROHHAD represents an autoimmune phenomenon precipitated by specific environmental exposures in an individual with a susceptible genetic background, as has been postulated for narcolepsy (29). This alternative could explain the variable timing of onset in the disease. Further research will be needed to ultimately determine the validity of the paraneoplastic and autoimmune hypotheses.

Recently, a case of monozygotic twins discordant for the ROHHAD phenotype was identified (29a). Although this discovery does not exclude the possibility that genetic variation is a causative factor in ROHHAD, it challenges the hypothesized monogenic cause and forces stronger consideration of alternate etiologies. Variation in the epigenomes of identical twins has been shown to accumulate quickly and throughout their lifetime, accounting for a great deal of discordance in phenotypes of twins (30). Variation in the epigenome has previously been found to plays a vital role in development of 
pediatric diseases of respiratory and autonomic function such as Prader-Willi and Rett Syndrome (31). The possibility that epigenetic variation plays a role in the development of ROHHAD will be analyzed in future studies.

Although this study is the largest published candidate gene analysis in ROHHAD to date, the small sample size remains a limitation. ROHHAD is a rare disease with only 76 cases reported worldwide $(2,8-12)$. Although this is likely a gross underestimate of the total ROHHAD population, identification and recruitment of patients with this disease is difficult. However, continued identification of patients with ROHHAD and refinement of the phenotype is extremely important due both to the devastating consequences of the phenotype itself (especially with late identification) and to the insight that the study of these patients can provide with regard to hypothalamic development and mechanisms underlying other disorders of obesity and of respiratory control. This study is further limited by the fact that only a subset of the cases in this cohort has been examined in the authors' centers. Although inclusion criteria were strict, and required thorough review of all available medical records in all cases by physicians with ROHHAD experience, classification of the children's symptoms as ROHHAD is best made after extensive in-laboratory clinical testing at centers with substantial experience with this disease.

This report provides evidence that genetic variation of the $H T R_{1 A}, O T P$, and PACAP genes as studied in our cohort is not responsible for ROHHAD. These results represent a further step in the investigation of the genetic determinants of ROHHAD. Future analysis of genes and networks acting in hypothalamic, autonomic, and neuroendocrine systems development and function will be required to ultimately determine which, if any of these, are dysfunctional in ROHHAD. These studies, in addition to further investigation of ROHHAD as a paraneoplastic, autoimmune, or epigenetic condition and continued study of ROHHAD patients in the clinical setting, will guide future research regarding disease etiology and ROHHAD treatment options.

\section{REFERENCES}

1. Fishman LS, Samson JH, Sperling DR 1965 Primary alveolar hypoventilation syndrome (Ondine's Curse). Am J Dis Child 110:155-161

2. Katz ES, McGrath S, Marcus CL 2000 Late-onset central hypoventilation with hypothalamic dysfunction: a distinct clinical syndrome. Pediatr Pulmonol 29:62-68

3. Amiel J, Laudier B, Attie-Bitach T, Trang H, de Pontual L, Gener B, Trochet D, Etchevers H, Ray P, Simonneau M, Vekemans M, Munnich A, Gaultier C, Lyonnet S 2003 Polyalanine expansion and frameshift mutations of the paired-like homeobox gene PHOX2B in congenital central hypoventilation syndrome. Nat Genet 33:459461

4. Berry-Kravis EM, Zhou L, Rand CM, Weese-Mayer DE 2006 Congenital central hypoventilation syndrome: PHOX2B mutations and phenotype. Am J Respir Crit Care Med 174:1139-1144

5. Weese-Mayer DE, Berry-Kravis EM, Zhou L, Maher BS, Silvestri JM, Curran ME Marazita ML 2003 Idiopathic congenital central hypoventilation syndrome: analysis of genes pertinent to early autonomic nervous system embryologic development and identification of mutations in PHOX2B. Am J Med Genet A 123A:267-278

6. Sasaki A, Kanai M, Kijima K, Akaba K, Hashimoto M, Hasegawa H, Otaki S, Koizumi T, Kusuda S, Ogawa Y, Tuchiya K, Yamamoto W, Nakamura T, Hayasaka K 2003 Molecular analysis of congenital central hypoventilation syndrome. Hum Genet 114:22-26

7. Trochet D, Bourdeaut F, Janoueix-Lerosey I, Deville A, de Pontual L, Schleiermacher G, Coze C, Philip N, Frebourg T, Munnich A, Lyonnet S, Delattre O, Amie
J 2004 Germline mutations of the paired-like homeobox 2B (PHOX2B) gene in neuroblastoma. Am J Hum Genet 74:761-764

8. Ize-Ludlow D, Gray JA, Sperling MA, Berry-Kravis EM, Milunsky JM, Farooqi IS, Rand CM, Weese-Mayer DE 2007 Rapid-onset obesity with hypothalamic dysfunction, hypoventilation, and autonomic dysregulation presenting in childhood. Pediatrics 120:e179-e188

9. De Pontual L, Trochet D, Caillat-Zucman S, Abou Shenab OA, Bougneres P, Crow Y, Cunningham S, Esteva B, Heberle LC, Leger J, Pinto G, Polak M, Shafik MH, Straus C, Trang H, Munnich A, Lyonnet S, Desguerre I, Amiel J 2008 Delineation of late onset hypoventilation associated with hypothalamic dysfunction syndrome. Pediatr Res 64:689-694

10. Bougnéres P, Pantalone L, Linglart A, Rothenbühler A, Le Stunff C 2008 Endocrine manifestations of the rapid-onset obesity with hypoventilation, hypothalamic, autonomic dysregulation and neural tumor syndrome in childhood. J Clin Endocrinol Metab 93:3971-3980

11. Onal H, Ersen A 2010 A case of late-onset central hypoventilation syndrome with hypothalamic dysfunction: through a new phenotype. Turk J Pediatr 52:198-202

12. Paz-Priel I, Cooke DW, Chen AR 2011 Cyclophosphamide for rapid-onset obesity, hypothalamic dysfunction, hypoventilation, and autonomic dysregulation syndrome J Pediatr 158:337-339

13. Yadav VK, Oury F, Suda N, Liu ZW, Gao XB, Confavreux C, Klemenhagen KC, Tanaka KF, Gingrich JA, Guo XE, Tecott LH, Mann JJ, Hen R, Horvath TL, Karsenty G 2009 A serotonin-dependent mechanism explains the leptin regulation of bone mass, appetite, and energy expenditure. Cell 138:976-989

14. Thor KB, Blitz-Siebert A, Helke CJ 1992 Autoradiographic localization of 5HT1 binding sites in autonomic areas of the rat dorsomedial medulla oblongata. Synapse 10:217-227

15. Thor KB, Blitz-Siebert A, Helke CJ 1992 Autoradiographic localization of 5HT1 binding sites in the medulla oblongata of the rat. Synapse 10:185-205

16. Bardet SM, Martinez-de-la-Torre M, Northcutt RG, Rubenstein JL, Puelles L 2008 Conserved pattern of OTP-positive cells in the paraventricular nucleus and other hypothalamic sites of tetrapods. Brain Res Bull 75:231-235

17. Das M, Vihlen CS, Legradi G 2007 Hypothalamic and brainstem sources of pituitary adenylate cyclase-activating polypeptide nerve fibers innervating the hypothalamic paraventricular nucleus in the rat. J Comp Neurol 500:761-776

18. Farnham MM, Li Q, Goodchild AK, Pilowsky PM 2008 PACAP is expressed in sympathoexcitatory bulbospinal $\mathrm{C} 1$ neurons of the brain stem and increases sympathetic nerve activity in vivo. Am J Physiol Regul Integr Comp Physiol 294:R1304R1311

19. Légrádi G, Shioda S, Arimura A 1994 Pituitary adenylate cyclase-activating polypeptide-like immunoreactivity in autonomic regulatory areas of the rat medulla oblongata. Neurosci Lett 176:193-196

20. Sundler F, Ekblad E, Hannibal J, Moller K, Zhang YZ, Mulder H, Elsas T, Grunditz T, Danielsen N, Fahrenkrug J, Uddman R 1996 Pituitary adenylate cyclaseactivating peptide in sensory and autonomic ganglia: localization and regulation. Ann N Y Acad Sci 805:410-426

21. Gray SL, Cummings KJ, Jirik FR, Sherwood NM 2001 Targeted disruption of the pituitary adenylate cyclase-activating polypeptide gene results in early postnatal death associated with dysfunction of lipid and carbohydrate metabolism. Mol Endocrinol 15:1739-1747

22. Adams BA, Gray SL, Isaac ER, Bianco AC, Vidal-Puig AJ, Sherwood NM 2008 Feeding and metabolism in mice lacking pituitary adenylate cyclase-activating polypeptide. Endocrinology 149:1571-1580

23. Cummings KJ, Willie C, Wilson RJ 2008 Pituitary adenylate cyclase-activating polypeptide maintains neonatal breathing but not metabolism during mild reductions in ambient temperature. Am J Physiol Regul Integr Comp Physiol 294:R956-R965

24. Cummings KJ, Pendlebury JD, Sherwood NM, Wilson RJ 2004 Sudden neonatal death in PACAP-deficient mice is associated with reduced respiratory chemoresponse and susceptibility to apnoea. J Physiol 555:15-26

25. Ouvrier R, Nunn K, Sprague T, McLean C, Arbuckle S, Hopkins I, North K 1995 Idiopathic hypothalamic dysfunction: a paraneoplastic syndrome? Lancet 346:1298

26. Sirvent N, Berard E, Chastagner P, Feillet F, Wagner K, Sommelet D 2003 Hypothalamic dysfunction associated with neuroblastoma: evidence for a new paraneoplastic syndrome? Med Pediatr Oncol 40:326-328

27. Didelot A, Honnorat J 2009 Update on paraneoplastic neurological syndromes. Curr Opin Oncol 21:566-572

28. Nath U, Grant R 1997 Neurological paraneoplastic syndromes. J Clin Pathol 50:975-980

29. Overeem S, Black JL 3rd, Lammers GJ 2008 Narcolepsy: immunological aspects. Sleep Med Rev 12:95-107

29a.Patwari PP, Rand CM, Berry-Kravis EM, Jennings LJ, Yu M, and Weese-Mayer DE: Rapid onset obesity with hypothalamic dysfunction, hypoventilation, and autonomic dysregulation (ROHHAD): Report on identical twins discordant for ROHHAD phenotype. Pediatrics, in press

30. Fraga MF, Ballestar E, Paz MF, Ropero S, Setien F, Ballestar ML, Heine-Suner D, Cigudosa JC, Urioste M, Benitez J, Boix-Chornet M, Sanchez-Aguilera A, Ling C, Carlsson E, Poulsen P, Vaag A, Stephan Z, Spector TD, Wu YZ, Plass C, Esteller M 2005 Epigenetic differences arise during the lifetime of monozygotic twins. Proc Natl Acad Sci USA 102:10604-10609

31. Hirasawa R, Feil R 2010 Genomic imprinting and human disease. Essays Biochem 48:187-200 